\title{
IN VITRO ANTAGONISTIC GROWTH EFFECTS OF LACTOBACILLUS FERMENTUM AND LACTOBACILLUS SALIVARIUS AND THEIR FERMENTATIVE BROTH ON PERIODONTAL PATHOGENS
}

\author{
Ling-Ju Chen ${ }^{1}$, Hsiu-Ting Tsai ${ }^{2}$, Wei-Jen Chen ${ }^{3}$, Chu-Yang Hsieh ${ }^{3}$, Pi-Chieh Wang ${ }^{4}$, Chung-Shih Chen ${ }^{5}$, Lina Wang ${ }^{6}$, \\ Chi-Chiang Yang ${ }^{6,7^{*}}$
}

${ }^{1}$ Department of Laboratory Medicine, Pojen General Hospital, Taipei, Taiwan, R.O.C.; ${ }^{2}$ School of Nursing, Chung Shan Medical University, Taichung, Taiwan, R.O.C.; ${ }^{3}$ Research and Development Department, Syngen Biotech Co. Ltd., Tainan, Taiwan, R.O.C.; ${ }^{4}$ Department of Dermatology, Pojen General Hospital, Taipei, Taiwan, R.O.C.; ${ }^{5}$ Institute of Biomedical Sciences and Technology, Chaoyang University of Technology, Wufeng, Taiwan, R.O.C.; 'School of Medical Laboratory and Biotechnology, Chung Shan Medical University, Taichung, Taiwan, R.O.C.; ${ }^{7}$ Department of Clinical Laboratory, Chung Shan Medical University Hospital, Taichung, Taiwan, R.O.C.

Submitted: February 24, 2010; Returned to authors for corrections: April 23, 2010; Approved: June 07, 2012.

\begin{abstract}
As lactobacilli possess an antagonistic growth property, these bacteria may be beneficial as bioprotective agents for infection control. However, whether the antagonistic growth effects are attributed to the lactobacilli themselves or their fermentative broth remains unclear. The antagonistic growth effects of Lactobacillus salivarius and Lactobacillus fermentum as well as their fermentative broth were thus tested using both disc agar diffusion test and broth dilution method, and their effects on periodontal pathogens, including Streptococcus mutans, Streptococcus sanguis, and Porphyromonas gingivalis in vitro at different concentrations and for different time periods were also compared. Both Lactobacillus salivarius and Lactobacillus fermentum and their concentrated fermentative broth were shown to inhibit significantly the growth of Streptococcus mutans, Streptococcus sanguis, and Porphyromonas gingivalis, although different inhibitory effects were observed for different pathogens. The higher the counts of lactobacilli and the higher the folds of concentrated fermentative broth, the stronger the inhibitory effects are observed. The inhibitory effect is demonstrated to be dose-dependent. Moreover, for the lactobacilli themselves, Lactobacillus fermentum showed stronger inhibitory effects than Lactobacillus salivarius. However, the fermentative broth of Lactobacillus fermentum showed weaker inhibitory effects than that of Lactobacillus salivarius. These data suggested that lactobacilli and their fermentative broth exhibit antagonistic growth activity, and consumption of probiotics or their broth containing lactobacilli may benefit oral health.
\end{abstract}

Key words: Lactobacillus fermentum, Lactobacillus salivarius, Streptococcus mutans, Streptococcus sanguis, Porphyromonas gingivalis, periodontitis.

*Corresponding Author. Mailing address: School of Medical Laboratory and Biotechnology, Chung Shan Medical University, 110, Section 1, Chien-Kuo North Road, Taichung, Taiwan 40201, R.O.C..; Tel: 886-4-24730022 ext. 12415 Fax: 886-4-23767469.; E-mail: cyang@csmu.edu.tw 


\section{INTRODUCTION}

Periodontitis, one of the most prevalent oral diseases, is associated with the imbalance of indigenous microbiota (10), and subsequently induces overgrowth of periodontal pathogens including Streptococcus mutans, Streptococcus sanguis, and Porphyromonas gingivalis $(10,21,25,27,28)$. To treat periodontitis, antibiotic therapy is usually administered along with traditional treatments, including scaling and root planning, for reducing the bacteria and preventing the recurrence of infection $(7,12)$. However, some individuals with periodontal disease respond neither to the treatment of scaling and root planning alone nor to treatment in combination with antibiotic therapy (32). Moreover, antibiotic resistance poses further problems, thus limiting the application of antibiotic therapy in the treatment of periodontitis $(30,31)$. Therefore, additional strategies on the use of probiotics in prevention and treatment of periodontal disease are strongly recommended.

Lactobacilli colonize naturally in the vagina and digestive tract, and possess antagonistic growth properties that offer protection from invasive pathogens (20). Genitourinary infections lead to a shift in the local flora from a predominance of lactobacilli to coliform uropathogens. Use of lactobacilluscontaining probiotics to restore commensal vaginal flora has been proposed for the treatment and prophylaxis of bacterial urogenital infections (6). Among lactobacilli genera, Lactobacillus salivarius and Lactobacillus fermentum are two of the most prevalent species in human saliva $(9,10)$. The genera belonging to this group can produce organic acids, such as lactic acid and acetic acid from carbohydrate fermentation, which can interfere with the growth of surrounding microorganisms and hydrogen peroxide which are antimicrobial substances (14). As lactobacilli possess an antagonistic growth property, these bacteria may be beneficial as bioprotective agents for infection control. Non-antibiotic therapy (25) has recently been applied in the treatment of periodontal diseases and has resolved the problem of antibiotic resistance $(30,31)$. However, whether the antagonistic growth activity is attributed to the lactobacilli themselves or their fermentative broth remains unclear.

The aim of this study was to determine the antagonistic growth effects of Lactobacillus salivarius and Lactobacillus fermentum as well as their fermentative broth on growth inhibition of periodontal pathogens, including Streptococcus mutans, Streptococcus sanguis, and Porphyromonas gingivalis. In the present study, the antagonistic growth effects of these two species of lactobacilli and their fermentative broth were tested using both disc agar diffusion test and broth dilution method. In addition, their effects on the three well-known periodontal pathogens in vitro at different concentrations and for different durations were also compared.

\section{MATERIALS AND METHODS}

\section{Bacterial strains and culture conditions}

Bacterial strains, including Streptococcus mutans (ATCC25175), Streptococcus sanguis (ATCC49295), and Porphyromonas gingivalis (ATCC33277) were purchased from Bioresource Collection and Research Center, Food Industry Research and Development Institute (Hsinchu, Taiwan, R.O.C.) and cultured according to the manufacturer's instructions. Streptococcus mutans was grown on tryptic soy broth (DIFCO 0369) with 5\% defibrinated sheep blood at $37^{\circ} \mathrm{C}$ under aerobic conditions. Streptococcus sanguis was grown on brain heart infusion (BHI) broth (DIFCO 0418) at $37^{\circ} \mathrm{C}$ under aerobic conditions. Porphyromonas gingivalis was grown on $\mathrm{BHI}-\mathrm{T}-\mathrm{C}$ medium at $37^{\circ} \mathrm{C}$ under anaerobic conditions. In a screening of our collection of 22 species of lactobacilli, Lactobacillus salivarius and Lactobacillus fermentum were the best two lactobacilli that demonstrated antagonistic growth properties. Both lactobacillus species, Lactobacillus fermentum (strain SG-A95) and Lactobacillus salivarius (strain SG-M6), provided by Syngen Biotech Co. Ltd. (Tainan, Taiwan) were cultured in Mann Rogosa Sharp (MRS) broth at $37^{\circ} \mathrm{C}$ under 
anaerobic conditions. $5 \times 10^{7} \mathrm{cfu}$ of Lactobacillus fermentum and Lactobacillus salivarius were cultured in $20 \mathrm{ml}$ MRS for 24 hours (hr) to prepare the fermented broth. The fermented broth of Lactobacillus salivarius and Lactobacillus fermentum were then centrifuged at $10,000 \mathrm{rpm}$ for 10 minutes (min) to remove the cell pellet and concentrated by a rotary vacuum evaporator at $60^{\circ} \mathrm{C}$ as the concentrated fermentative broth. In order to reduce the salts present in the concentrated fermentative broth, dialysis with a membrane (Spectra/Por ${ }^{2}$ ialysis Membrane; MWCO:3500, Spectrum Laboratories Inc, CA, USA) was performed for $48 \mathrm{hr}$ before subsequent experiments. The fermentative broth and the lactobacilli themselves were stored at $-80^{\circ} \mathrm{C}$ until required (Flowchart 1).

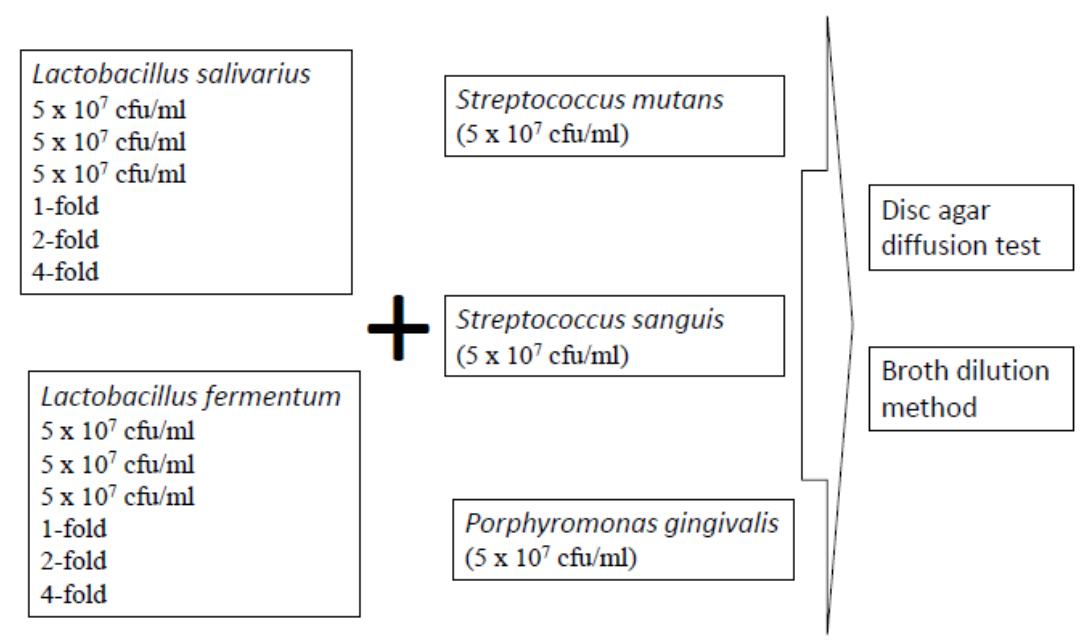

Flowchart 1. Summarizing the preparation steps involved in the present study.

\section{Disc agar diffusion test}

Paper discs infused with different concentrations of fermented MRS were placed on the surface of agar plates inoculated with the three different bacteria mentioned above, and incubated at $37^{\circ} \mathrm{C}$ for $24 \mathrm{hr}$ in triplicate. Distilled water and $250 \mathrm{mg} / \mathrm{mL}$ of tetracycline were used as negative and positive controls, respectively. Each sample was tested by three repeated analyses. The diameter of the inhibition zone around the disc was measured (mm). The diameter of the inhibition zone for the negative control (dist. water) was $6 \mathrm{~mm}$.

\section{Broth dilution method}

One milliliter of Lactobacillus salivarius or Lactobacillus fermentum suspension stock at counts of $5 \times 10^{7} \mathrm{cfu} / \mathrm{ml}, 5 \times 10^{8}$ $\mathrm{cfu} / \mathrm{ml}$ or $5 \times 10^{9} \mathrm{cfu} / \mathrm{ml}$; or 2 -fold or 4 -fold concentrated fermented broth of Lactobacillus salivarius or Lactobacillus fermentum was co-cultured with $1 \mathrm{ml}$ of Streptococcus mutans, Streptococcus sanguis, or Porphyromonas gingivalis at a count of $5 \times 10^{7} \mathrm{cfu} / \mathrm{ml}$ under periodontal bacteria's culture conditions as described above for different durations. The numbers of periodontal bacterial strains, i.e. Streptococcus mutans, Streptococcus sanguis, and Porphyromonas gingivalis, were counted at each time point and compared with unused MRS co-cultured with bacterial strains (negative controls). The number of bacterial strains was calculated by plating on agar plates as described above. Each sample was tested by three repeated analyses. The percentage of inhibitory was calculated as $100 \%$ - [(Test group $\div$ Control $) \times 100 \%]$.

\section{Statistical analysis}

Experimental results are presented as mean values. The Kruskal-Wallis test was employed to detect the difference in 
in growth inhibition of periodontal pathogens among three or more than three groups, and Scheffe correction was performed to check statistically significant difference between groups. $P$ value of less than 0.01 was considered significant. The data were analyzed using SPSS version 17.0 (SPSS Inc., Chicago, IL, USA) statistical software.

\section{RESULTS}

\section{Disc agar diffusion test}

The growth inhibitory effects of the fermentative broth of
Lactobacillus fermentum and Lactobacillus salivarius on Streptococcus mutans, Streptococcus sanguis, and Porphyromonas gingivalis were demonstrated by disc agar diffusion test. The inhibitory diameters of different concentrations of Lactobacillus fermentum and Lactobacillus salivarius fermentative broth were shown in Table 1 . Significant inhibitory effects of the fermentative broth of both Lactobacillus fermentum and Lactobacillus salivarius at different concentrations were demonstrated except for that at 1fold concentration.

Table 1. Growth inhibitory effects of fermentative broth of Lactobacillus fermentum and Lactobacillus salivarius on Streptococcus mutans, Streptococcus sanguis, and Porphyromonas gingivalis obtained by disc agar diffusion test $(\mathrm{n}=3)$.

\begin{tabular}{cccc}
\hline Product & Streptococcus mutans & Streptococcus sanguis & Porphyromonas gingivialis \\
\hline LFP 1-fold & $6.0 \pm 0.0$ & $6.0 \pm 0.0$ & $6.2 \pm 0.2$ \\
LFP 2-fold & $7.6 \pm 0.9$ & $7.7 \pm 1.0$ & $9.2 \pm 1.0$ \\
LFP 4-fold & $13.2 \pm 1.2$ & $12.4 \pm 1.2$ & $9.7 \pm 0.6$ \\
LSP 1-fold & $6.1 \pm 0.0$ & $6.0 \pm 0.0$ & $6.6 \pm 0.5$ \\
LSP 2-fold & $9 \pm 1.0$ & $9 \pm 1.0$ & $12 \pm 1.0$ \\
LSP 4-fold & $13 \pm 1.0$ & $16 \pm 1.0$ & $14 \pm 1.0$ \\
Tetracycline & $29.7 \pm 2.0$ & $25.9 \pm 1.2$ & $33.4 \pm 2.2$ \\
Distilled water & $6.0 \pm 0.0$ & $6.0 \pm 0.0$ & $6.0 \pm 0.0$ \\
\hline
\end{tabular}

LFP: Lactobacillus fermentum fermentative broth;

LSP: Lactobacillus salivarius fermentative broth

\section{Broth dilution method}

One milliliter of Lactobacillus fermentum or Lactobacillus salivarius suspension stock at counts of $5 \times 10^{7} \mathrm{cfu} / \mathrm{ml}, 5 \times 10^{8}$ $\mathrm{cfu} / \mathrm{ml}$, or $5 \times 10^{9} \mathrm{cfu} / \mathrm{ml}$ was co-cultured with $1 \mathrm{ml}$ of $5 \times 10^{7}$ $\mathrm{cfu} / \mathrm{ml}$ Streptococcus mutans, Streptococcus sanguis, or Porphyromonas gingivalis under these periodontal bacteria's culture conditions for different durations. Growth titers of Streptococcus mutans, Streptococcus sanguis, and Porphyromonas gingivalis counted at different time points were used as negative controls for comparison (Fig. 1). The results are shown on Fig. 2. Significant growth inhibitory effects $(\mathrm{p}<0.01)$ were observed when lactobacilli were cocultured with the pathogenic bacteria at a $1: 1$ ratio $\left(5 \times 10^{7}\right.$ $\mathrm{cfu} / \mathrm{ml})$. The higher the count $\left(5 \times 10^{8} \mathrm{cfu} / \mathrm{ml}\right.$ or $\left.5 \times 10^{9} \mathrm{cfu} / \mathrm{ml}\right)$ of Lactobacillus fermentum or Lactobacillus salivarius treated, the higher the growth inhibitory effects $(\mathrm{p}<0.01)$ on Streptococcus mutans, Streptococcus sanguis, and Porphyromonas gingivalis were observed (Fig. 2). Moreover, lactobacilli at a higher ratio (100:1) exhibited stronger growth inhibitory effects on the three pathogenic bacteria tested than those at a lower ratio (10:1 or 1:1). For example, growth of Streptococcus mutans was completely inhibited after $48 \mathrm{hr}$ of 
1- (5 x $\left.10^{7} \mathrm{cfu} / \mathrm{ml}\right), 10-\left(5 \times 10^{8} \mathrm{cfu} / \mathrm{ml}\right)$ or 100 -fold $\left(5 \times 10^{9}\right.$ $\mathrm{cfu} / \mathrm{ml})$ Lactobacillus fermentum treatment.

For Streptococcus sanguis, significant growth inhibition effects $(\mathrm{p}<0.01)$ by $1-\left(5 \times 10^{7} \mathrm{cfu} / \mathrm{ml}\right), 10-\left(5 \times 10^{8} \mathrm{cfu} / \mathrm{ml}\right)$, and 100 -fold $\left(5 \times 10^{9} \mathrm{cfu} / \mathrm{ml}\right)$ of Lactobacillus fermentum or Lactobacillus salivarius treatment were also found (Fig. 2). For example, the growth of Streptococcus sanguis was completely inhibited after $14 \mathrm{hr}$ of 1- and10-fold or $10 \mathrm{hr}$ of 100-fold Lactobacillus fermentum treatment, respectively.
For Porphyromonas gingivalis, when co-cultured with $5 \times 10^{7}$ $\mathrm{cfu} / \mathrm{ml}, 5 \times 10^{8} \mathrm{cfu} / \mathrm{ml}$ or $5 \times 10^{9} \mathrm{cfu} / \mathrm{ml}$ Lactobacillus fermentum or Lactobacillus salivarius, significant growth inhibitory effects $(\mathrm{p}$ $<0.01$ ) were also demonstrated (Fig. 2). For example, the growth of Porphyromonas gingivalis was completely inhibited after $14 \mathrm{hr}$ of 1-fold, $8 \mathrm{hr}$ of 10 -fold or $6 \mathrm{hr}$ of 100-fold Lactobacillus fermentum treatment, respectively. For the three oral pathogens tested, Lactobacillus fermentum showed stronger inhibitory effects than Lactobacillus salivarius.

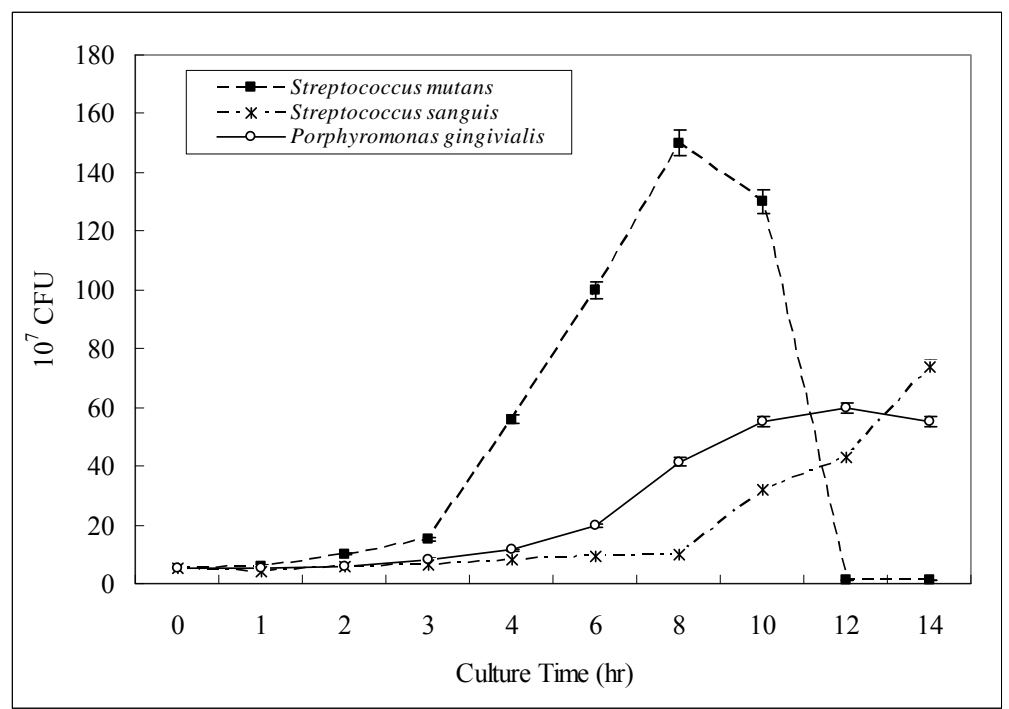

Figure 1. Growth curves of Streptococcus mutans, Streptococcus sanguis, and Porphyromonas gingivalis tested at different time points and used as negative controls for test on inhibitory effects $(n=3)$.

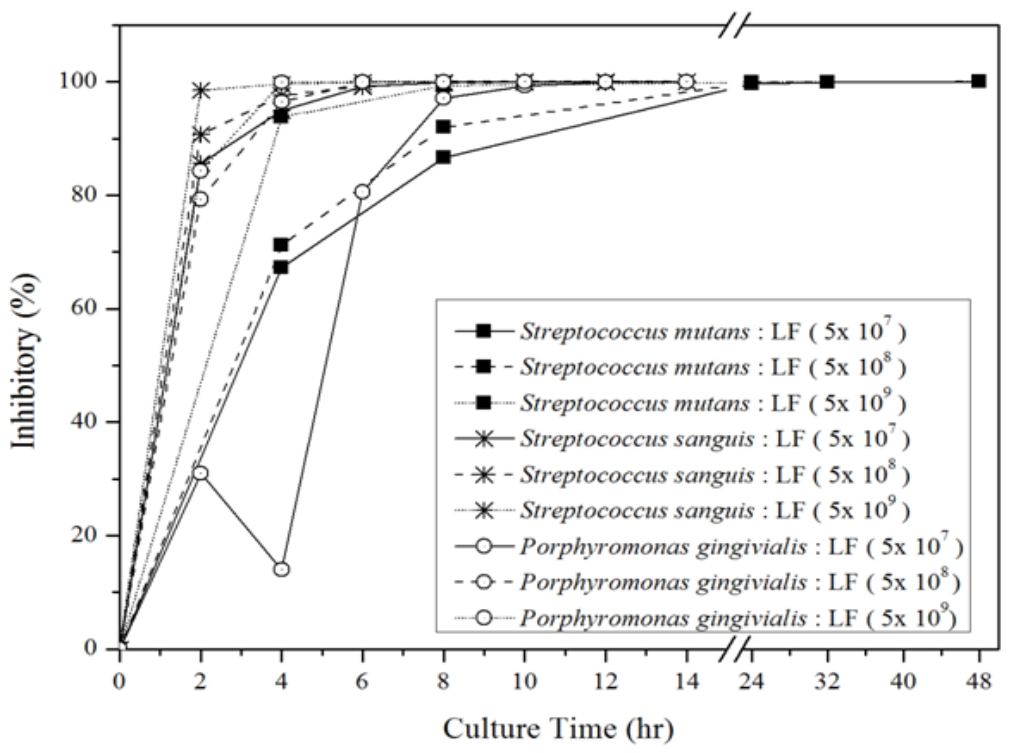

a) 


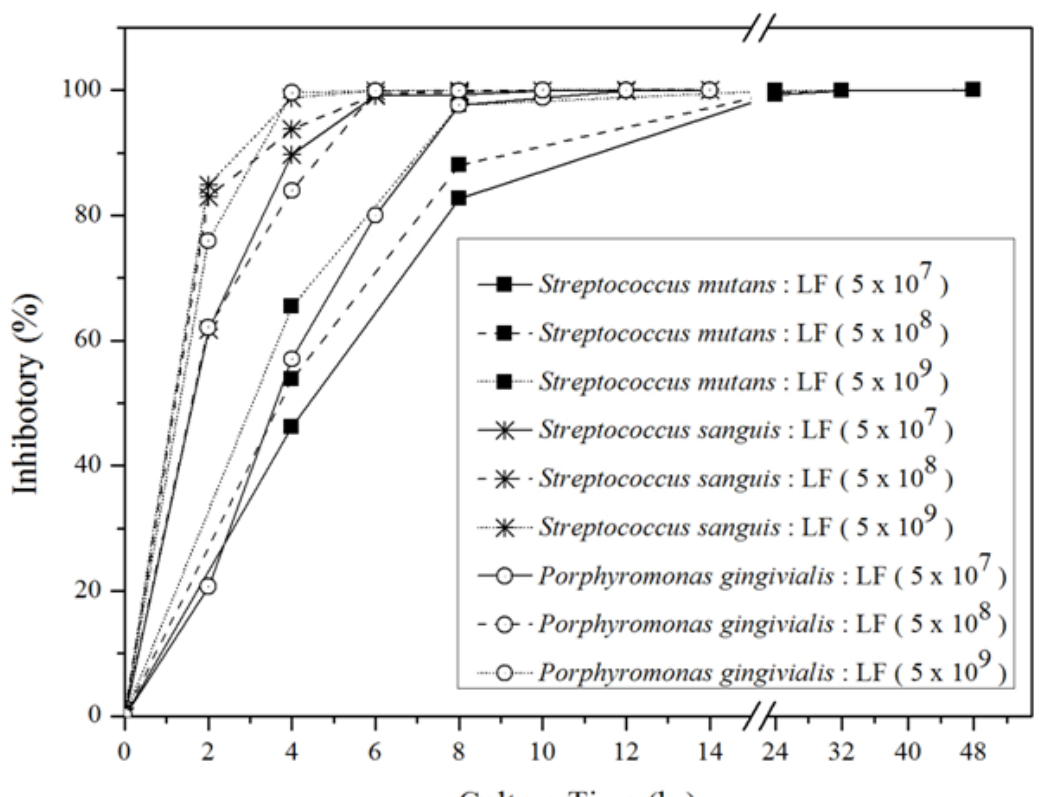

b)

Culture Time (hr)

Figure 2. Growth inhibitory percentages of different counts of (a) Lactobacillus fermentum or (b) Lactobacillus salivarius on $5 \mathrm{x}$ $10^{7} \mathrm{cfu} / \mathrm{ml}$ Streptococcus mutans, Streptococcus sanguis, and Porphyromonas gingivalis at different time points $(\mathrm{n}=3)$.

Since 1-fold fermentative broth of Lactobacillus fermentum and Lactobacillus salivarius did not show significant inhibitory effects by disc agar diffusion test, 2- and 4-fold concentrated fermentative broth were thus used for test. The broth dilution method demonstrated significant growth inhibitory effects of the concentrated fermentative broth of Lactobacillus fermentum and Lactobacillus salivarius on periodontal pathogens (Fig. 3). Both 2- and 4-fold concentrated fermentative broth of Lactobacillus fermentum and Lactobacillus salivarius inhibited significantly the growth of periodontal pathogens, including Streptococcus mutans, Streptococcus sanguis, and Porphyromonas gingivalis. However, the fermentative broth of Lactobacillus fermentum showed weaker inhibitory effects than that of Lactobacillus salivarius.

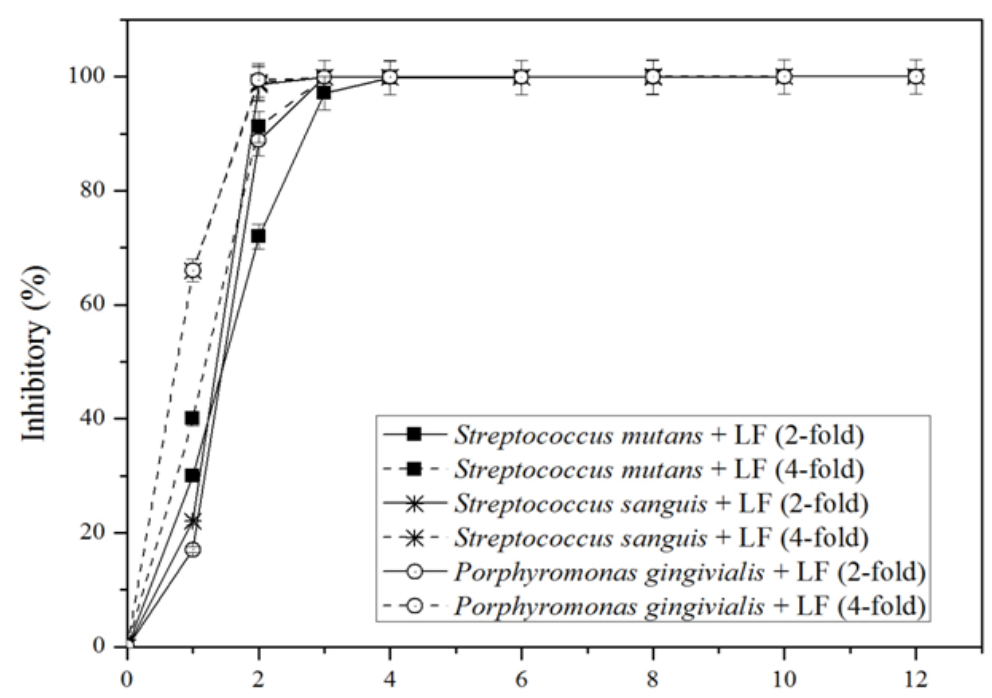

a)

Culture Time (hr) 


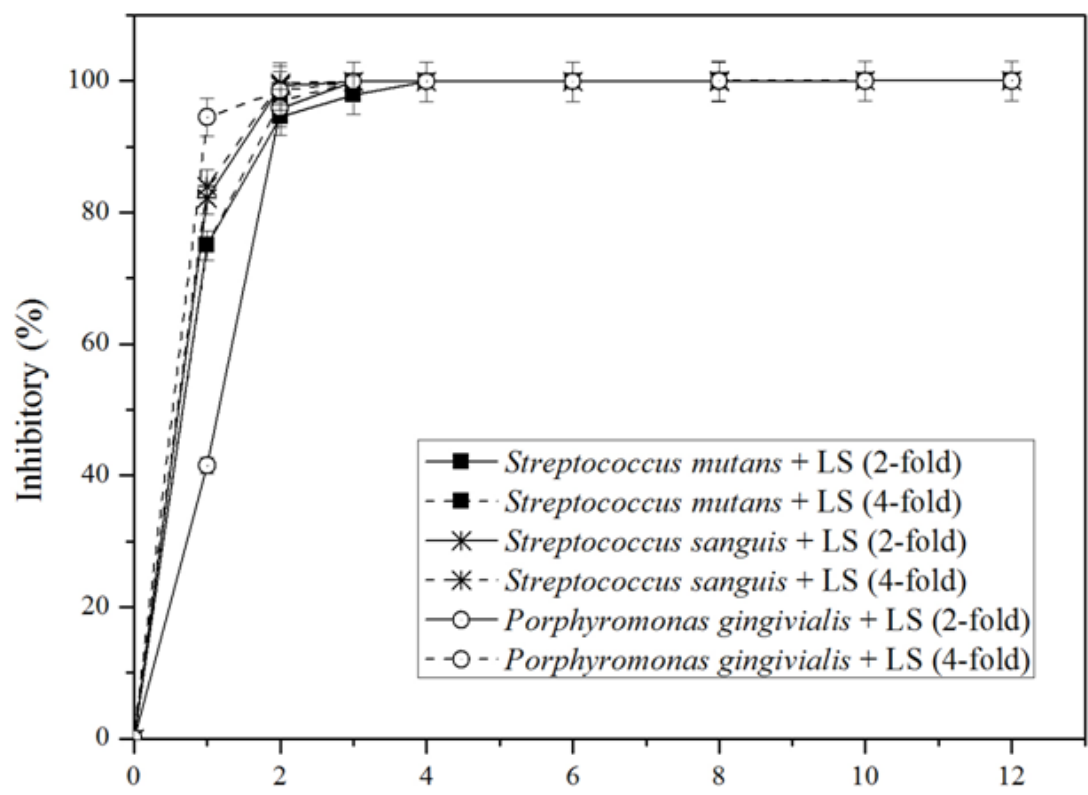

b)

Culture Time (hr)

Figure 3. Growth inhibitory effect of different folds of concentrated (a) Lactobacillus fermentum or (b) Lactobacillus salivarius fermentative broth on $5 \times 10^{7} \mathrm{cfu} / \mathrm{ml}$ Streptococcus mutans, Streptococcus sanguis, and Porphyromonas gingivalis at different time points $(n=3)$.

\section{DISCUSSION}

Probiotics are defined as microorganisms that generally confer a health benefit on humans $(5,8)$. Lactobacilli, which have been consumed daily by millions of people around the world for perceived health benefits, have been regarded as safe. Intestinal lactobacilli have been successfully used as probiotics to treat gastrointestinal disorders, but only limited data on the probiotic properties of oral lactobacilli for combating oral diseases are available. The use of probiotics in clinical trials should be accompanied by knowledge of the antagonistic growth susceptibilities of the organism used (24). In the present study, lactobacilli and their fermentative broth were tested in vitro for their potential probiotic properties for oral health. Both Lactobacillus salivarius and Lactobacillus fermentum and their fermentative broth were shown to inhibit the growth of three periodontal pathogens, i.e., Streptococcus mutans, Streptococcus sanguis, and Porphyromonas gingivalis, although different inhibitory effects were observed for different pathogens. Moreover, the higher the counts of lactobacilli and the higher the folds of concentrated fermentative broth, the stronger the inhibitory effects were, indicating that the inhibitory effect was dose-dependent.

In the lactobacilli genera, it was reported that strains of Lactobacillus salivarius, Lactobacillus plantarum, Lactobacillus paracasei, and Lactobacillus rhamnosus expressed high antimicrobial activity (11). Lactobacillus salivarius CECT5713 has recently been shown not only to be the best for in vitro antibacterial activity, but has also been found to possess the highest protective effect against a Salmonella strain in the murine infection model (19). Lactobacillus salivarius CELA2 (a bacteriocin-producing strain) was shown to display the highest probiotic potential in the gastrointestinal tract (13). Lactobacillus fermentum strain L23 and Lactobacillus rhamnosus strain L60 were suggested for prevention and treatment of urogenital infections in women, in view of their probiotic properties and production of bacteriocins (23). Short-term consumption of cheese containing 
Lactobacillus rhamnosus GG and Lactobacillus rhamnosus LC705 has been shown to reduce the risk of Streptococcus mutans in young adults, although their long-term effects remain unclear (1). Application of Lactobacillus reuteri was found to result in reduced gum bleeding and gingivitis. Oral lactobacilli flora has also been shown to inhibit the growth of Porphyromonas gingivalis and Prevotella intermedia (10). Taken together, our data are consistent with other findings indicating that lactobacilli and their fermentative broth exhibit antagonistic growth activity and consumption of probiotics or their broth containing lactobacilli can prevent or treat periodontal disease $(2,17,18)$. These results suggest a potential for the two lactobacilli species and their fermented broths to be used as probiotics and functional products, respectively for oral health.

Moreover, for the lactobacilli themselves, Lactobacillus fermentum showed stronger inhibitory effects than Lactobacillus salivarius. However, the fermentative broth of Lactobacillus fermentum showed weaker inhibitory effects than that of Lactobacillus salivarius. The mechanisms of probiotic action in the mouth are supposed to be similar to that observed in gastrointestinal tracts (15). Nevertheless, data on oral probiotics are yet insufficient. Probiotics has been used as passive local immunization vehicles to improve oral immune response and to prevent against oral diseases $(2,29)$. Recent reports on the search of antimicrobial protein/compounds produced by lactic acid bacteria have been increasing $(4,16$, 22, 26). Furthermore, probiotics produce organic acids including lactic, acetic and formic acids, which lower $\mathrm{pH}$ and oxidation-reduction potential and may suppress harmful organisms. It is possible that the mechanism of action is attributed to the organic acids produced by the probiotics and present in the fermentative broth. However, in view of the difference in antibacterial potential between the two lactobacilli and their fermentative broth, such possibility was rather low. It was thus suggested the two lactobacilli species themselves may undergo different mechanisms to exhibit inhibitory effects on oral pathogens, e.g. the lacotobacilli may compete with oral pathogens for growth nutrients or growth space, which is different from the replication inhibition underwent by the antimicrobial protein/compounds in the fermentative broth. Further investigation is needed to elucidate this assumption.

In conclusion, we have demonstrated through in vitro growth inhibitory test that Lactobacillus fermentum and Lactobacillus salivarius and their concentrated fermentative broth inhibit significantly periodontal pathogens, including Streptococcus mutans, Streptococcus sanguis, and Porphyromonas gingivalis in a dose-dependent manner. Consumption of probiotics or their broth containing lactobacilli may benefit oral health. However, further and extensive researches including human studies are needed.

\section{ACKNOWLEDGEMENTS}

This study was funded by grants from the Chung Shan Medical University (CSMU 98-OM-A-169 and 99-CSMUPGH-02).

\section{REFERENCES}

1. Ahola, A.J.; Yli-Knuuttila, H.; Suomalainen, T.; Poussa, T.; Ahlstrom, A.; Meurman, J.H.; Korpela, R. (2002). Short-term consumption of probiotic-containing cheese and its effect on dental caries risk factors. Arch. Oral Biol. 47, 799-804.

2. Çglar, E.; Kargul, B.; Tanboga, I. (2005). Bacteriotherapy and probiotics' role on oral health. Oral Dis. 11, 131-137.

3. Çaglar, E.; Kuscu, O.O.; Kuvvetli, S.S.; Cildir, S.K.; Sandalli, N.; Twetman, S. (2008). Short-term effect of ice-cream containing Bifidobacterium lactis $\mathrm{Bb}-12$ on the number of salivary mutans streptococci and lactobacilli. Acta Odontol. Scand. 66, 154-158.

4. Clare, D.A.; Zheng, Z.; Hassan, H.M.; Swaisgood, H.E.; Catignani, G.L. (2008). Antimicrobial properties of milkfat globule membrane fractions. J. Food Prot. 71, 126-133.

5. de Vrese, M.; Schrezenmeir, J. (2008). Probiotics, prebiotics, and synbiotics. Adv. Biochem. Eng. Biotechnol. 111, 1-66.

6. Dover, S.E.; Aroutcheva, A.A.; Faro, S.; Chikindas, M.L. (2007). Safety study of an antimicrobial peptide lactocin 160, produced by the vaginal Lactobacillus rhamnosus. Infect. Dis. Obstet. Gynecol. 2007, 78248.

7. Greenstein, G.; Polson, A. (1998). The role of local drug delivery in the management of periodontal diseases: a comprehensive review. $J$. 
Periodontol. 69, 507-520.

8. Gupta, V.; Garg, R. (2009). Probiotics. Indian J. Med. Microbiol. 27, 202-209.

9. Hojo, K.; Mizoguchi, C.; Taketomo, N.; Ohshima, T.; Gomi, K.; Arai, T.; Maeda, N. (2007). Distribution of salivary Lactobacillus and Bifidobacterium species in periodontal health and disease. Biosci., Biotechnol., Biochem. 71, 152-157.

10. Koll-Klais, P.; Mandar, R.; Leibur, E.; Marcotte, H.; Hammarstrom, L.; Mikelsaar, M. (2005). Oral lactobacilli in chronic periodontitis and periodontal health: species composition and antimicrobial activity. Oral Microbiol. Immunol., 20, 354-361.

11. Koll, P.; Mandar, R.; Marcotte, H.; Leibur, E.; Mikelsaar, M.; Hammarstrom, L. (2008). Characterization of oral lactobacilli as potential probiotics for oral health. Oral Microbiol. Immunol. 23, 139147.

12. Mariotti, A.; Monroe, P.J. (1998). Pharmacologic management of periodontal diseases using systemically administered agents. Dent. Clin. North Am. 42, 245-262.

13. Martin, R.; Delgado, S.; Maldonado, A.; Jimenez, E.; Olivares, M.; Fernandez, L.; Sobrino, O.J.; Rodriguez, J.M. (2009). Isolation of lactobacilli from sow milk and evaluation of their probiotic potential. $J$. Dairy Res. 76, 418-425.

14. McGroarty, J.A.; Tomeczek, L.; Pond, D.G.; Reid, G.; Bruce, A.W. (1992). Hydrogen peroxide production by Lactobacillus species: correlation with susceptibility to the spermicidal compound nonoxynol9. J. Infect. Dis. 165, 1142-1144.

15. Meurman, J.H. ; Stamatova, I. (2007). Probiotics: contributions to oral health. Oral Diseases 13, 443-51.

16. Millette, M.; Dupont, C.; Archambault, D.; Lacroix, M. (2007). Partial characterization of bacteriocins produced by human Lactococcus lactis and Pediococccus acidilactici isolates. J. Appl. Microbiol. 102, 274-282.

17. Nase, L.; Hatakka, K.; Savilahti, E.; Saxelin, M.; Ponka, A.; Poussa, T.; Korpela, R.; Meurman, J.H. (2001). Effect of long-term consumption of a probiotic bacterium, Lactobacillus rhamnosus GG, in milk on dental caries and caries risk in children. Caries Res. 35, 412-420.

18. Nikawa, H.; Makihira, S.; Fukushima, H.; Nishimura, H.; Ozaki, Y.; Ishida, K.; Darmawan, S.; Hamada, T.; Hara, K.; Matsumoto, A.; Takemoto, T.; Aimi, R. (2004). Lactobacillus reuteri in bovine milk fermented decreases the oral carriage of mutans streptococci. Int. J. Food Microbiol. 95, 219-223.

19. Olivares, M.; Diaz-Ropero, M.P.; Martin, R.; Rodriguez, J.M.; Xaus, J. (2006). Antimicrobial potential of four Lactobacillus strains isolated from breast milk. J. Appl. Microbiol. 101, 72-79.

20. Orrhage, K.; Nord, C.E. (2000). Bifidobacteria and lactobacilli in human health. Drugs Exp. Clin. Res. 26, 95-111.
21. Ouhara, K.; Komatsuzawa, H. ; Yamada, S. ; Shiba, H. ; Fujiwara, T. ; Ohara, M. ; Sayama, K.; Hashimoto, K.; Kurihara, H.; Sugai, M. (2005). Susceptibilities of periodontopathogenic and cariogenic bacteria to antibacterial peptides, -defensins and LL37, produced by human epithelial cells. J. Antimicrob. Chemother. 55, 888-896.

22. Rojo-Bezares, B.; Saenz, Y.; Zarazaga, M.; Torres, C.; Ruiz-Larrea, F. (2007). Antimicrobial activity of nisin against Oenococcus oeni and other wine bacteria. Int. J. Food Microbiol. 116, 32-36.

23. Ruiz, F.O.; Gerbaldo, G.; Asurmendi, P.; Pascual, L.M.; Giordano, W.; Barberis, I.L. (2009). Antimicrobial activity, inhibition of urogenital pathogens, and synergistic interactions between lactobacillus strains. Curr. Microbiol. 59, 497-501.

24. Snydman, D.R. (2008). The safety of probiotics. Clin. Infect. Dis. 46, Suppl 2, S104-11; discussion S144-51.

25. Spacciapoli, P.; Buxton, D.; Rothstein, D.; Friden, P. (2001). Antimicrobial activity of silver nitrate against periodontal pathogens. $J$. Periodontal Res. 36, 108-113.

26. Sutyak, K.E.; Wirawan, R.E.; Aroutcheva, A.A.; Chikindas, M.L. (2008). Isolation of the Bacillus subtilis antimicrobial peptide subtilosin from the dairy product-derived Bacillus amyloliquefaciens. J. Appl. Microbiol. 104, 1067-1074.

27. Taubman, M.A.; Han, X.; Larosa, K.B.; Socransky, S.S.; Smith, D.J. (2007). Periodontal bacterial DNA suppresses the immune response to mutans streptococcal glucosyltransferase. Infect. Immun. 75, 4088-4096.

28. Thiha, K.; Takeuchi, Y.; Umeda, M.; Huang, Y.; Ohnishi, M.; Ishikawa, I. (2007). Identification of periodontopathic bacteria in gingival tissue of Japanese periodontitis patients. Oral Microbiol. Immunol. 22, 201-207.

29. Vancikova, Z., Lodinova-Zadnikova, R., Radl, J. Tlaskalová-Hogenová, H. (2003). The early postnatal development of salivary antibody and immunoglobulin response in children orally colonized with a nonpathogenic, probiotic strain of E. coli. Folia Microbiol. (Praha) 48: 281-287.

30. van Winkelhoff, A.J.; Herrera, D.; Winkel, E.G.; Dellemijn-Kippuw, N.; Vandenbroucke-Grauls, C.M.; Sanz, M. (1999). Antibiotic resistance in the subgingival microflora in patients with adult periodontitis. A comparative survey between Spain and the Netherlands. Ned Tijdschr Tandheelkd. 106, 290-294.

31. van Winkelhoff, A.J.; Herrera Gonzales, D.; Winkel, E.G.; DellemijnKippuw, N.; Vandenbroucke-Grauls, C.M.; Sanz, M. (2000). Antimicrobial resistance in the subgingival microflora in patients with adult periodontitis. A comparison between the Netherlands and Spain. $J$. Clin. Periodontol. 27, 79-86.

32. Wasserman, B.; Hirschfeld, L. (1988). The relationship of initial clinical parameters to the long-term response in 112 cases of periodontal disease. J. Clin. Periodontol. 15, 38-42. 